\title{
Understanding critical disability studies
}

I n the spring of 1918, after three years of fighting on the Western Front, a 25-year-old soldier in the Canadian army was sent to a series of military hospitals in France, the United Kingdom and eventually Cobourg, Ontario, after which, he was discharged as "medically unfit" due to "sickness" in 1919. He had what was then known as "shell shock." After the war, he seldom spoke to his family about his experiences, other than to describe the 1917 Battle of Passchendaele as "mud, noise and death." Like many veterans, World War I haunted him for the rest of his life. His name was Francis Udall, and he was my maternal grandfather.

In the emergent field of critical disability studies, my grandfather's experiences, like those of so many who have been traumatized by war and conflict, are understood in the context of the barriers society placed on these soldiers - barriers that served to pathologize, confine and ostracize them. Above all else, this new discipline allows disability — madness in this case - to be understood from the perspective of the person who experiences it, as much as this is possible. One hundred years after the start of the war that gave rise to the term "shell shock," there exists a field of study that recognizes the expertise of disabled people in understanding their own life, while advocating for progressive societal change.

Critical disability studies view disability as both a lived reality in which the experiences of people with disabilities are central to interpreting their place in the world, and as a social and political definition based on societal power relations.
Emerging from the activism of disabled people in the 1970s, this area of study involves both academics and activists representing multiple disciplines and perspectives. It challenges approaches that pathologize physical, mental and sensory

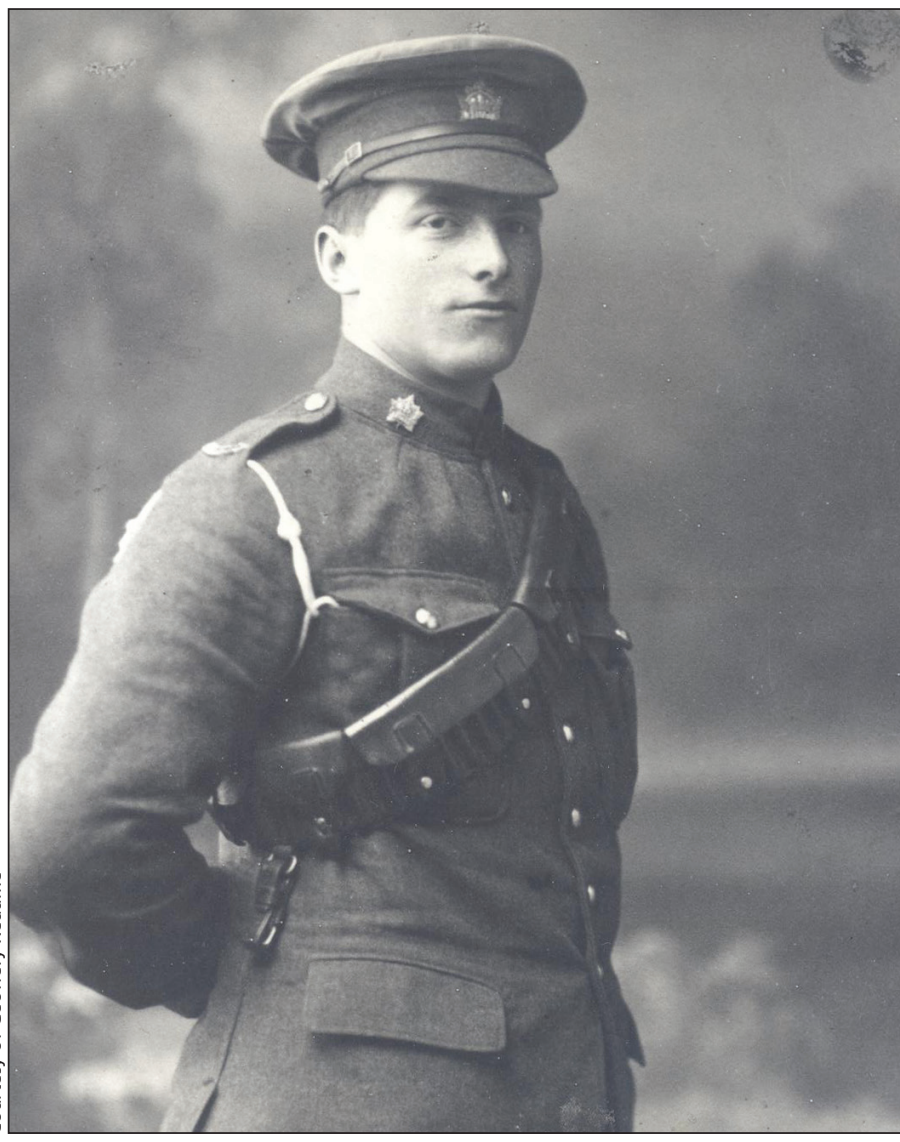

Francis Udall in 1915, in England, before leaving for France and Belgium.

under the scrutiny of critical disability studies, a field that works toward universal accessibility.

Changing public attitudes toward disabilities is important. Some argue that the term "disabled people" emphasizes that disability is an essential part of self-identity. Others argue that the term "people with disabilities" stresses that functional limitation is only one aspect of overall identity. Neither term is universally accepted. As language changes, so too will these terms, but the very fact that this debate exists reflects the efforts of a long-marginalized community to assert how they should be defined on their own terms.

In some cases, people categorized as disabled reject the term outright; for example, people who identify as "Deaf" with a capital "D" argue they are a linguistic minority who do not have a disability. Thus, even within the field itself there are people who prefer to be thought of as other than disabled. Critical disability studies also examines how disability intersects with race, gender, class and sexuality in ways that influence wider power

difference as being in need of correction, and instead advocates for both accommodation and equality for disabled people in all areas of life. Critical disability studies seek to change conventional notions of disabled people as pitiable, tragic victims who should adjust to the world around them. This charity model is criticized for providing badly needed services without engaging the underlying causes of social exclusion. Barriers to education, employment, transportation and a host of services, both public and private, all come relations and personal experiences.

Included in these interpretations are several analytical models developed by activists and academics. The "social model of disability," interprets disability as a construct imposed by external powers (e.g., medical, legal and governmental systems). In this model, there is a difference between impairment - a practical restriction — and disability — a difference promoted by society without considering impairments. The "rights model of disability," advocates for legal change to 
address inequities with the view that disabled people deserve equal rights and access. The "cultural model of disability" focuses on how the reality of disability is understood within a cultural context as an experience that can be positive but also lead to discrimination and physical and psychological pain.

These models are the subject of much debate and revision, as are other approaches not included here; there is no single way to understand and address the effects of excluding people from society based on a label of disability. What is central is understanding and including disabled people as the experts in their own past and present. In this sense, critical disability studies aim to reinterpret what it means to be considered disabled, bringing people who live this experience to the process as the primary agents of change in word and deed. A major part of this work is therefore to ensure that this field is by, not just about, disabled people.

My grandfather spent most of his last two years on a psychiatric ward of a veteran's hospital before dying in 1974 at the age of 81. Right around the time Francis Udall died, activists in various parts of the world were organizing to advocate that people with various forms of disability — sensory, mental or physical — be thought of as engaged citizens rather than as neglected outcasts. Although the definition of an inclusive society tends to recalibrate over time, critical disability studies aims to relegate injustices toward disabled people to the past.

\section{Geoffrey Reaume PhD}

Critical Disability Studies

York University

Toronto, Ont.

CMAJ 2014. DOI:10.1503/cmaj.141236

See Appendix 1 (available at www .cmaj.ca/lookup/suppl/doi:10.1503/cmaj $.141236 /-/ D C 1)$ for further reading on disability studies.

\section{BOOKS}

\section{A robust future}

\author{
Medicine, Health and the Arts: \\ Approaches to the medical humanities \\ Victoria Bates, Alan Bleakley, Sam \\ Goodman, editors \\ Routledge; 2014
}

$\mathrm{T}$ he term "medical humanities" was first coined in 1947. Sixtyseven years later, this wonderful new collection of essays, that is part of the "Routledge Advances in the Medical Humanities" book series, shows how the discipline has progressed and points the way to a robust future. Alan Bleakley, one of the editors, goes so far as to say that medical humanities can democratize medicine by challenging the ingrained hierarchies that lead to poor team work and ineffective patient consultation.

Whether or not this is true, all 14 commissioned essays call for a broader and more inclusive definition of the medical humanities and more reciprocity and exchange among the players. This would entail a sustained, interdisciplinary inquiry into the aspects of practice, education and research that are expressly concerned with the human side of medicine, including the interpretation of experiences of illness, disability and medical intervention. The arts for health movement, which puts the voices of patients first, has generally been excluded from academic teaching of the humanities. The contributors to this book argue that including the voices of patients and caregivers, as well as engaging artists and humanities scholars as equal partners, are essential to the next iteration of the field. Considerable political will and action are required to integrate the medical humanities into the biomedical model, rather than treating it as an add-on or an extra bit of "flavouring" within the medical enterprise.

This essay collection gives ample examples of what medical humanities offers. Each of the five sections - an overview of the medical humanities in Britain and beyond, visual arts, performance, music, and literature and writing - emphasize that by engaging with art, we contemplate beauty and accept complexity; we are therefore better able to tolerate uneasiness, anxiety and uncertainty. Surely this is what is required of healers in the modern world.

Medicine, Health and the Arts also explores the challenges of research in the medical humanities field. The preference for quantitative research by biomedicine and granting agencies means that the qualitative techniques used to explore the impact of arts on health have been underused and disrespected. To keep up with the times, the new "critical medical humanities" will have to bridge quantitative and qualitative research methods, challenge granting agencies and find new ways to ask questions.

I have but one critique of this book. Some of the authors suggest that the close reading of literary texts has become instrumentalized in medical education and does not actually lead to increased empathy in learners. Yet, research, particularly in the neurosciences, has shown that reading does increase empathy, not only for doctors, but also for anyone who fully engages with a literary text (work in this area was done in Toronto by cognitive psychologist Keith Oatley). Some of the established critiques and pet peeves of scholars within the medical humanities field will need to be revisited in the light of such emerging scholarship.

Medicine, Health and the Arts is an enjoyable read and will allow those already working in the field to expand their vision of what the medical humanities can be. For those new to the discipline, this text will stimulate joyful collaborations and new possibilities.

\author{
Allan Peterkin MD \\ Program in Health, Arts and Humanities \\ University of Toronto \\ Toronto, Ont.
}

CMAJ 2014. DOI:10.1503/cmaj.140079 